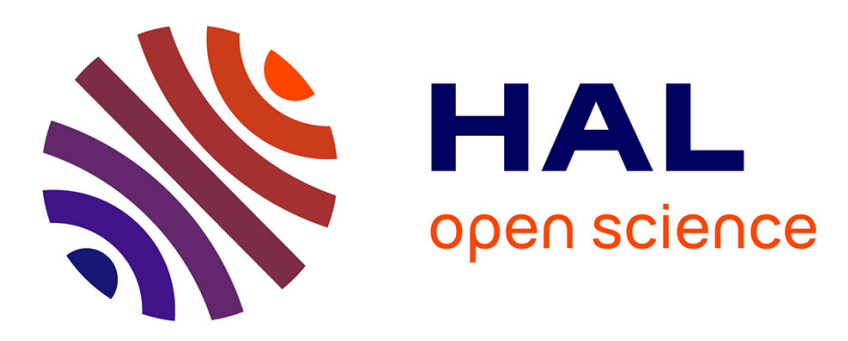

\title{
Development of new alumina precipitation routes for catalysis applications
}

Robin Lafficher, Mathieu Digne, Fabien Salvatori, Malika Boualleg, Didier Colson, François Puel

\section{- To cite this version:}

Robin Lafficher, Mathieu Digne, Fabien Salvatori, Malika Boualleg, Didier Colson, et al.. Development of new alumina precipitation routes for catalysis applications. Journal of Crystal Growth, 2017, 468, pp.526-530. 10.1016/j.jcrysgro.2016.11.092 . hal-01534077

\section{HAL Id: hal-01534077 \\ https://hal.science/hal-01534077}

Submitted on 7 Jun 2017

HAL is a multi-disciplinary open access archive for the deposit and dissemination of scientific research documents, whether they are published or not. The documents may come from teaching and research institutions in France or abroad, or from public or private research centers.
L'archive ouverte pluridisciplinaire HAL, est destinée au dépôt et à la diffusion de documents scientifiques de niveau recherche, publiés ou non, émanant des établissements d'enseignement et de recherche français ou étrangers, des laboratoires publics ou privés. 
This Accepted author version available online: 29 Nov 2016.

To cite this article: Robin Lafficher, Mathieu Digne, Fabien Salvatori, Malika Boualleg, Didier Colson, Francois Puel (2017) Development of new alumina precipitation routes for catalysis applications., Journal of Crystal Growth, 468, 526-530, DOI: 10.1016/j.jcrysgro.2016.11.092

Development of new alumina precipitation routes for catalysis applications

Robin Lafficher $^{* a, b}$, Mathieu Digne ${ }^{\mathrm{a}}$, Fabien Salvatori ${ }^{\mathrm{a}}$, Malika Boualleg ${ }^{\mathrm{a}}$, Didier Colson ${ }^{\mathrm{b}}$, François Puel $^{\mathrm{c}}$

${ }^{*}$ Corresponding author Tel: +33 4.37.70.21.15

Email: fabien.salvatori@ifpen.fr (Fabien Salvatori)

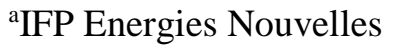 \\ BP 3, F-69360 Solaize, France \\ bUniv Lyon, Universite Lyon 1, CNRS, UMR5007, LAGEP \\ 43 bd du 11 Novembre 1918, F-69622 Lyon, France \\ 'LGPM, Laboratoire de Génie des Procédés et Matériaux, CentraleSupélec, Université Paris-Saclay \\ Grande Voie des Vignes, 92295 Châtenay-Malabry, France
}

\begin{abstract}
$\gamma$-Alumina is a widely used porous material for catalytic application. Possible routes for alumina improvement can be the use of alternative precursors as well as innovative precipitation technologies. In this study, we compare the influence of both precursor chemistry and mixing efficiency on $\gamma$-alumina properties. The conventionally used boehmite and the $\mathrm{NH}_{4}$-dawsonite precursors were precipitated using three mixing technologies: a conventional stirred-tank reactor, a rotor-stator mixer and a sliding surface mixing device. It was observed that, in the study conditions, $\gamma$-alumina mean pore diameter and porous volume were particularly sensitive to both precursor and mixing technology, while specific surface area was rather precursor dependent. A wide porosity range can thus be covered at isospecific surface area, using several precursor/mixing technology systems.
\end{abstract}

Keywords

A1. Precipitation

A1. Micromixing

B1. Alumina

B1. Dawsonite

\title{
1. Introduction
}

Supported heterogeneous catalysts are widely used in refining and petrochemical processes. One way to better catalyst performances is to develop supports with enhanced properties. The properties of alumina-based catalyst supports are to a large extent fixed by the properties of the initial solid precursor, such as boehmite (AlOOH) [1]. Various synthesis routes are possible for alumina precursors: sol-gel process, using aluminium alkoxides [2], can lead to pure alumina with high thermal stability and surface area in the range of 200-500 $\mathrm{m}^{2} \cdot \mathrm{g}^{-1}$ [3]; moreover, the use of various copolymers as structure-directing 
agents can lead to ordered materials and enable good control of the porosity [4,5]. However, precipitation of aluminium salts in aqueous solution represents a cheaper way for alumina production at an industrial scale, even though these alumina generally exhibit surface areas lower than $300 \mathrm{~m}^{2} \cdot \mathrm{g}^{-1}[6,7]$ and may have high impurities contents $\left(200-3000 \mathrm{ppm} \mathrm{Na}_{2} \mathrm{O}\right)[1,8]$. In this context, possible routes for alumina improvement can lie in the use of alternative precursors as well as innovative precipitation technologies compared to the commonly used stirred tank reactor. Such a combination could lead to new textural properties.

Ammonium dawsonite $\left(\mathrm{NH}_{4} \mathrm{Al}(\mathrm{OH})_{2} \mathrm{CO}_{3}\right)$ can be an interesting alternative choice for preparation of $\gamma-\mathrm{Al}_{2} \mathrm{O}_{3}$ with high purity level and new textural properties [9]. Various methods can be used to synthesize this precursor [10], but the main one remains the precipitation in aqueous phase of aluminium salts $\left(\mathrm{Al}\left(\mathrm{NO}_{3}\right)_{3},\left(\mathrm{NH}_{4}\right) \mathrm{Al}\left(\mathrm{SO}_{4}\right)_{2}\right.$, or $\left.\mathrm{AlCl}_{3}\right)$ with precipitating agents such as $\left(\mathrm{NH}_{4}\right)_{2} \mathrm{CO}_{3}$ or $\mathrm{NH}_{4} \mathrm{HCO}_{3}$.

As precipitation of sparingly soluble materials, such as boehmite or $\mathrm{NH}_{4}$-dawsonite, is generally associated with very fast reactions, the solid properties can be strongly influenced by mixing quality [11]. Therefore, the choice of the mixing technology is particularly important. The most commonly used reactor for precipitation is the stirred tank reactor in batch or semi-batch configuration. However, this technology suffers from two important drawbacks: the specific power dissipated by the stirrer is not homogeneously distributed in the whole reactor [12], and, due to discontinuous operation, precipitation conditions change throughout the process [9]. Using fast contacting mixers in continuous configuration could allow a better supersaturation control thanks to a more efficient mixing, while maintaining constant precipitation conditions throughout the process.

With this work, we present a comparative study of different $\gamma$-alumina properties, prepared by precipitation of boehmite or $\mathrm{NH}_{4}$-dawsonite, using three mixing technologies: a stirred tank reactor (STR) operated in semi-batch, and two fast mixers operated continuously, a sliding surface mixing device (SSMD) and a rotor-stator mixer (RSM). This work complements previous studies on boehmite precipitation with SSMD technology [13] and $\mathrm{NH}_{4}$-dawsonite precipitation with $\mathrm{RSM}$ technology [9].

\section{Experimental set-up}

Precipitated boehmite was synthesized at $60{ }^{\circ} \mathrm{C}$ from an aluminium sulphate solution (A) and a sodium aluminate solution (B) by simultaneous dosing of the reactants, with molar ratio $R_{B / A}=4$. Precipitated $\mathrm{NH}_{4}$-dawsonite was synthesized at $60^{\circ} \mathrm{C}$ from an aluminium nitrate solution (A') and a carbonate ammonium solution (B') by simultaneous dosing of the reactants, with molar ratio $\mathrm{R}_{\mathrm{B}^{\prime} / \mathrm{A}^{\prime}}=8$.

The 3.5-L glass baffled STR used in this study is equipped with a three blade propeller TTP Mixel. The stirring speed was fixed so that the mean specific dissipated power $\bar{\varepsilon}=0.2 \mathrm{~W} . \mathrm{kg}^{-1}$. The feed points were located in the discharge stream of the impeller, where the specific energy dissipation is the highest. Boehmite synthesis were set up at a constant $\mathrm{pH}$ of 9.7 and at final alumina concentration $\left[\mathrm{Al}_{2} \mathrm{O}_{3}\right]=36$ g. $\mathrm{L}^{-1}$. Dawsonite synthesis were set up at $\mathrm{pH}$ between 7.5 and 8.5, and at final alumina concentration $\left[\mathrm{Al}_{2} \mathrm{O}_{3}\right]=8$ g.L $\mathrm{L}^{-1}$

The SSMD (Fig. 1a) was designed based on the device presented by Rousseau et al [14]. It consists of a stainless steel cylindrical chamber in which is located a $120 \mathrm{~mm}$ large rotating disc. The gap $\mathrm{h}$ between the disc and the chamber flat bottom can be adjusted between 1 and $3 \mathrm{~mm}$. Reactants were injected in the confined mixing zone under the disc through a central feed tube (A or A') and four lateral symmetrical feed tubes (B or B'), situated at equal distance $r=40 \mathrm{~mm}$ from the center. Boehmite synthesis were set up at $\mathrm{pH}$ between 9.1 and 9.9, and at final alumina concentration $\left[\mathrm{Al}_{2} \mathrm{O}_{3}\right]=36$ g.L $\mathrm{L}^{-1}$. Dawsonite synthesis were set up at $\mathrm{pH} 7.5$ and 8.5, and at final alumina concentration $\left[\mathrm{Al}_{2} \mathrm{O}_{3}\right]=10$ g.L1 .

The RSM (Fig. 1b) used in this study is a DK40 from CAT, equipped with a double feed system. The rotor radius is $r_{R}=16.5 \mathrm{~mm}$ and the gap between rotor and stator is $\mathrm{e}=1 \mathrm{~mm}$. Boehmite synthesis were set up at $\mathrm{pH}$ between 8.5 and 9.5, and at final alumina concentration $\left[\mathrm{Al}_{2} \mathrm{O}_{3}\right]=12$ g. $\mathrm{L}^{-1}$. Dawsonite synthesis were set up at $\mathrm{pH} 7.5$ and 8.0 , and at final alumina concentration $\left[\mathrm{Al}_{2} \mathrm{O}_{3}\right]=10$ g.L. ${ }^{-1}$.

As flow rates in continuous mixers (SSMD, RSM) were much higher than that in STR, precipitation duration was shorter for a same final suspension volume. A precise $\mathrm{pH}$ control was therefore more complicated, which explains the slight differences observed depending on the mixer used. However, the 
repeatability was tested for some operating conditions with the three mixers, and was satisfying according the precipitated solids properties.

Following the synthesis, suspensions were filtered, washed with water and dried at $120^{\circ} \mathrm{C}$ for $14 \mathrm{~h}$. The dried precursors (noted $\mathrm{B} / \mathrm{xxx}$ and $\mathrm{D} / \mathrm{xxx}$, for boehmite and $\mathrm{NH}_{4}$-dawsonite respectively, $\mathrm{xxx}$ corresponding to the mixer used: STR, SSMD or RSM) were then calcined at $500{ }^{\circ} \mathrm{C}$ for $4 \mathrm{~h}$ to obtain $\gamma-\mathrm{Al}_{2} \mathrm{O}_{3}$ final support (noted $\mathrm{Al}-\mathrm{B} / \mathrm{xxx}$ and $\mathrm{Al}-\mathrm{D} / \mathrm{xxx}$, for boehmite derived and $\mathrm{NH}_{4}$-dawsonite derived alumina, respectively, $\mathrm{xxx}$ corresponding to the mixer used)

Solids were characterized by X-ray diffraction (XRD) and thermogravimetric analysis (TGA) to determine their crystallinity and purity. Their textural properties (specific surface area $\mathrm{S}_{\mathrm{BET}}$, pore volume $\mathrm{V}_{\mathrm{p}}$ and mean pore diameter $\mathrm{D}_{\mathrm{p}}$ ) were determined by using nitrogen adsorption analysis.

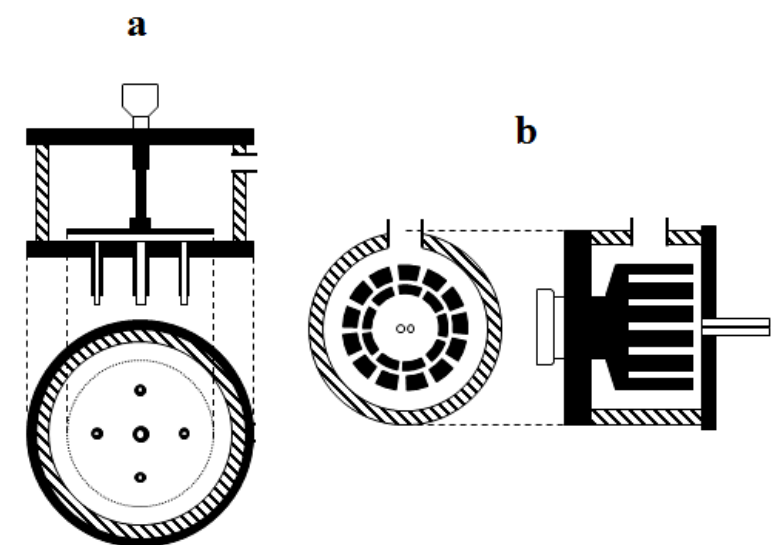

Fig. 1. Schematic representation of fast contacting mixers : (a) SSMD and (b) RSM

\section{Results and discussion}

\subsection{Precipitation in stirred tank reactor}

First, boehmite and $\mathrm{NH}_{4}$-dawsonite have been precipitated in the STR in semi-batch mode. Both precursors and derived aluminas were characterized in order to be used as references for the rest of the study.

As confirmed by powder XRD analysis, precipitation of aluminium sulphate with sodium aluminate led to the obtention of boehmite (ICDD 21-1307) and precipitation of aluminium nitrate with ammonium carbonate led to the obtention of $\mathrm{NH}_{4}$-dawsonite (ICDD 42-0250). Neither crystalline mixed boehmite and $\mathrm{NH}_{4}$-dawsonite phases, nor other crystalline phases, were detected. Average crystallite sizes were determined using Scherrer's equation.

Physical properties of both precursors and their derived aluminas are summarized in Table 1 . In the studied conditions, $\mathrm{NH}_{4}$-dawsonite exhibited larger crystallites than boehmite. As a consequence, the precursors displayed quite different textural properties. Despite a similar pore volume, $\mathrm{NH}_{4}$-dawsonite indeed exhibited a lower specific surface area but a mean pore diameter four times higher. It can be noted that mean pore diameters of both precursors were broadly consistent with their respective average crystallite sizes, even though boehmite seemed to present a more compact aggregation than $\mathrm{NH}_{4}$ dawsonite. After calcination at $500{ }^{\circ} \mathrm{C}$, a strong increase of porosity and specific surface area was noted in the case of dawsonite derived alumina: its pore volume reached $1.0 \mathrm{~cm}^{3} \cdot \mathrm{g}^{-1}$, and its specific surface area outreached $420 \mathrm{~m}^{2} \cdot \mathrm{g}^{-1}$, leading to a solid with superior textural properties compared to boehmite derived alumina. Interestingly, we noted that decreasing the $\mathrm{NH}_{4}$-dawsonite reactants molar ratio from 8 to 3 led to an increase of the derived alumina porosity, with pore volume near $1.2 \mathrm{~cm}^{3} \cdot \mathrm{g}^{-1}$, mean pore diameter in the range of $30 \mathrm{~nm}$ and specific surface area still higher than $400 \mathrm{~m}^{2} \cdot \mathrm{g}^{-1}$.

However, it turns out that an important part of the dawsonite derived alumina specific surface area is due to microporosity. This can be explained by the thermal decomposition process of $\mathrm{NH}_{4}$-dawsonite, in which $\mathrm{H}_{2} \mathrm{O}, \mathrm{NH}_{3}$ and $\mathrm{CO}_{2}$ are released in important quantities, leading to the formation of intracrystalline porosity [15]. Indeed, $\mathrm{NH}_{4}$-dawsonite mass loss measured by TGA is in the range of 
$60 \%$, which is close to the theoretical value of $63 \%$. On the contrary, boehmite only lost $23 \%$ mass, corresponding to both dehydration of hydroxyl groups and physisorbed water.

Table 1. Physical properties of precursors and derived aluminas precipitated in the STR

\begin{tabular}{cccccc}
\hline Sample & $\begin{array}{c}\mathrm{L}^{\mathrm{a}} \\
(\AA)\end{array}$ & $\begin{array}{c}\mathrm{S}_{\mathrm{BET}} \\
\left(\mathrm{m}^{2} \cdot \mathrm{g}^{-1}\right)\end{array}$ & $\begin{array}{c}\mathrm{S}_{\text {micro }} \mathrm{b} \\
\left(\mathrm{m}^{2} \cdot \mathrm{g}^{-1}\right)\end{array}$ & $\begin{array}{c}\mathrm{V}_{\mathrm{p}} \\
\left(\mathrm{cm}^{3} \cdot \mathrm{g}^{-1}\right)\end{array}$ & $\begin{array}{c}\mathrm{D}_{\mathrm{p}} \\
(\mathrm{nm})\end{array}$ \\
\hline $\mathrm{B} / \mathrm{STR}$ & 47 & 286 & 0 & 0.70 & 3.9 \\
$\mathrm{D} / \mathrm{STR}$ & 114 & 198 & 0 & 0.72 & 16.3 \\
$\mathrm{Al}-\mathrm{B} / \mathrm{STR}$ & - & 299 & 7 & 0.83 & 5.6 \\
Al-D/STR & - & 428 & 198 & 1.01 & $2.7-16.4$ \\
\hline $\begin{array}{l}{ }^{a} \text { Average crystallite size determined using Scherrer's equation. } \\
\text { using Determined }\end{array}$ \\
uslot method.
\end{tabular}

\subsection{Fast-mixer influence}

In SSMD case, the mixing influence on the solid properties was investigated with the following operating parameters: the disc rotational speed $(\mathrm{N}=150-2000 \mathrm{rpm})$, the total reactants flow rate $\left(\mathrm{Q}=150-2500 \mathrm{ml} \cdot \mathrm{min}^{-1}\right)$ and the confined mixing zone height under the disc $(\mathrm{h}=1-3 \mathrm{~mm})$. Micromixing times were directly determined using Eq. (1), proposed by Rousseaux et al. [14] in case of a laminar flow in the confined mixing zone.

In RSM case, the mixing influence on the solids properties were investigated with the following operating parameter: the rotor rotational speed $(\mathrm{N}=2500-7000 \mathrm{rpm})$. Micromixing times were determined using Eq. (2) [16], the specific power dissipated being estimated using Eq. (3) [17]. This correlation was adapted from rotor-stator in batch configuration and did not account for the potential flow rate influence. However, since studies on specific power dissipated by rotor-stator mixers are still very empirical, and so limited to the studied tool, there is no general correlation for in-line rotor-stator mixers [18].

The studied micromixing times range from 1 to $4 \mathrm{~ms}$ on the RSM, and from 10 to $180 \mathrm{~ms}$ on the SSMD. In comparison, STR micromixing time in the studied conditions, estimated with Eq. (2) and (4), is in the range of 15 ms. However, for a given micromixing time, continuous configuration still allows a better control of the supersaturation as the environment in which supersaturation occurs remains the same during the whole precipitation process.

$$
\begin{aligned}
& t_{m}=\frac{1}{\sqrt{0.0090\left(\frac{r N}{h}\right)^{2}+0.065\left(\frac{Q}{r}\right)^{2} \frac{1}{h^{4}}}} \\
& t_{m}=17,2 \sqrt{\frac{v}{\varepsilon}} \\
& \varepsilon=\frac{v \omega^{2} r_{R}^{2}}{e^{2}} \\
& \varepsilon=\Phi \cdot \bar{\varepsilon}=\Phi \frac{N_{P} N^{3} D_{a}^{5} \rho}{m}
\end{aligned}
$$

The mixing influence on boehmite and $\mathrm{NH}_{4}$-dawsonite crystallographic and textural properties was thus studied. As in the precipitation in STR, the precursor purity was first verified by XRD and TG 
analysis. The mass losses measured during a thermal treatment of the precursors precipitated with fast contacting mixers were in the same range as that of the precursors precipitated in the STR.

It can be clearly noted on Fig. 2 that precipitation in a fast contacting mixer led to a decrease in the precursor respective crystallite size, from 15 to $40 \%$, compared to precipitation in STR. Moreover, we can observe that the crystallite size is sensitive to the micromixing time, and increased with it, particularly in $\mathrm{NH}_{4}$-dawsonite case. This is consistent with a better supersaturation control at smaller micromixing times: a higher supersaturation level is thus reached, leading to a more intense primary nucleation kinetic, and so to a crystallite size decrease.

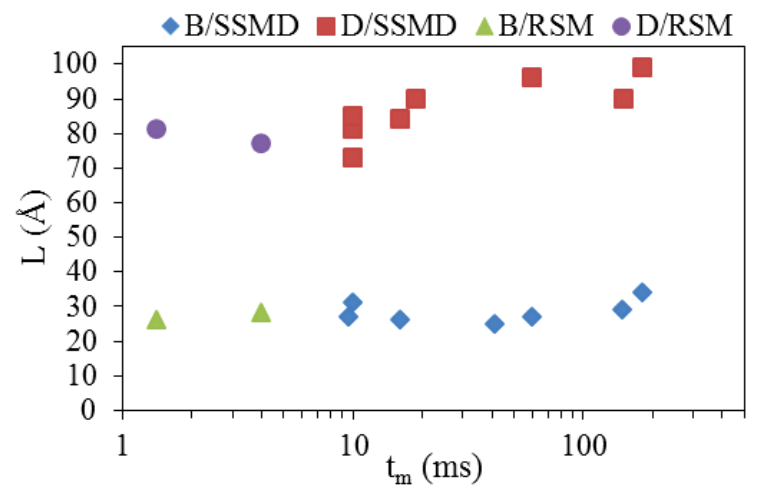

Fig. 2. Precursors crystallite size $(\mathrm{L})$ evolution with micromixing time $\left(\mathrm{t}_{\mathrm{m}}\right)$ for different fast contacting mixers

Fig. 3 presents the alumina textural properties evolution with micromixing time for both fast contacting mixers. In boehmite derived alumina case (products Al-B/SSMD and Al-B/RSM), micromixing time does not seem to have a major influence on the textural properties of the solids: both the specific surface area and the pore volume remained approximately constant, ranging from 250 to $300 \mathrm{~m}^{2} \cdot \mathrm{g}^{-1}$ and from 0.3 to $0.4 \mathrm{~cm}^{3} \cdot \mathrm{g}^{-1}$, respectively. Only the solid precipitated at micromixing time of $1 \mathrm{~ms}$ exhibited a higher specific surface area, near $350 \mathrm{~m}^{2} \cdot \mathrm{g}^{-1}$. Furthermore, no effect of the fast contacting mixer type can be observed, as the textural properties obtained with the RSM are in the SSMD's continuity. On the contrary, dawsonite derived alumina (products Al-D/SSMD and Al-D/RSM) showed a biggest sensitivity to micromixing. If the specific surface variations between the precursors precipitated at various micromixing time (data not shown) finally disappeared after the calcination step, the pore volume remains particularly sensitive to this parameter. This lead to alumina exhibiting specific surface area higher than $400 \mathrm{~m}^{2} \cdot \mathrm{g}^{-1}$ and tunable pore volume between 0.5 and $0.9 \mathrm{~cm}^{3} \cdot \mathrm{g}^{-1}$. However, it is more difficult in that case to determine a potential influence of the fast contacting mixer in the same range of micromixing time, as the pore volume can vary from 0.5 to $0.7 \mathrm{~cm}^{3} \cdot \mathrm{g}^{-1}$ for micromixing times between 1 and $10 \mathrm{~ms}$.
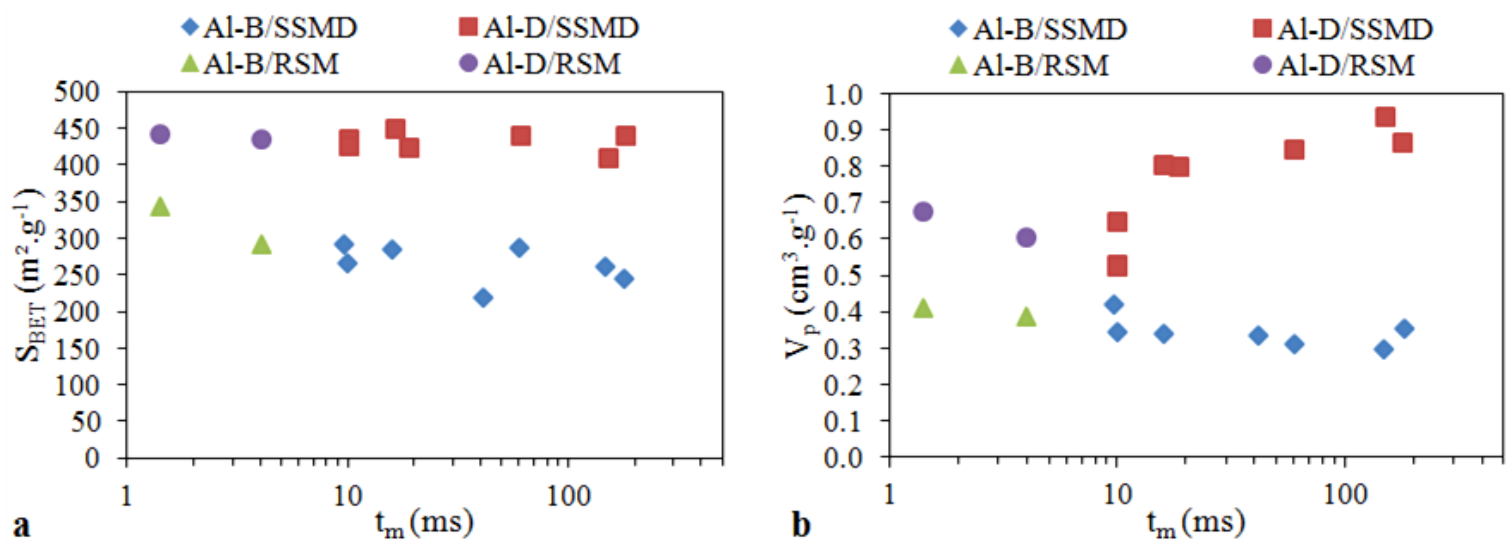
Fig. 3. (a) Specific surface area and (b) pore volume evolution with micromixing time of boehmite and $\mathrm{NH}_{4}$-dawsonite derived alumina prepared with different fast contacting mixers

Overall, it can be noted that alumina prepared by precipitation in fast mixers exhibit a specific surface area relatively close to that of alumina prepared in STR (or a bit lower for some boehmite derived alumina), but a lower porosity.

In the case of boehmite derived alumina, this trend can be observed on the whole micromixing time range studied. Fig. 4 shows the $\mathrm{N}_{2}$ adsorption-desorption isotherms and pore size distributions trend obtained with the three mixers. Alumina prepared with both fast mixers exhibited very close properties, but differed from the one prepared with the STR. Since the hysteresis loops are representative of the pore network shape, we can assume that crystallite arrangement depends on the use of semi-batch or continuous mixers, but not on the micromixing time.

In the case of dawsonite derived alumina, we can observe that at high micromixing times, the textural properties of alumina prepared with SSMD tend towards that of alumina prepared with STR. Comparison of $\mathrm{N}_{2}$ adsorption-desorption isotherms and pore size distributions (Fig. 5) confirms the micromixing influence on these alumina porosity. Indeed, for micromixing times shorter than $15 \mathrm{~ms}$, pore network shape and pore size distribution obtained with both fast contacting mixers were similar. However, alumina prepared in the SSMD at micromixing times higher than 15 ms exhibited intermediate properties between those obtained with the RSM and the STR. Thus, $\mathrm{NH}_{4}$-dawsonite appears to be more sensitive than boehmite to micromixing time in the studied range. Those two trends could be explained by precipitation kinetics with very different intensities, depending on the precursor.
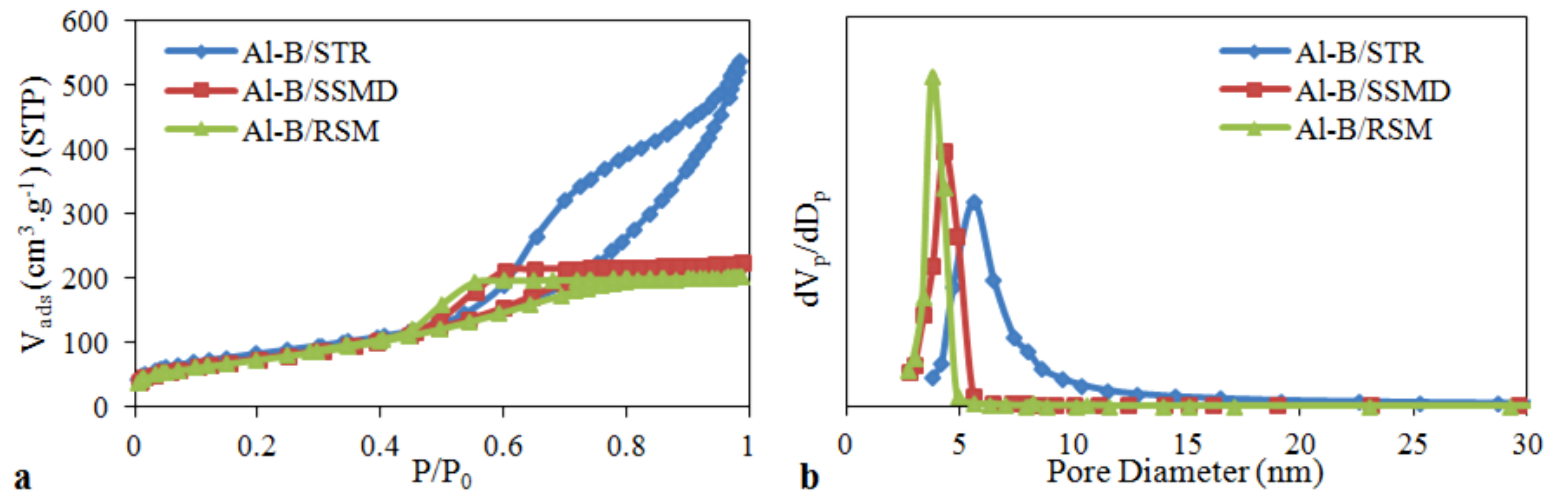

Fig. 4. (a) $\mathrm{N}_{2}$ adsorption-desorption isotherm and (b) pore size distributions of boehmite derived alumina prepared with different mixing technologies
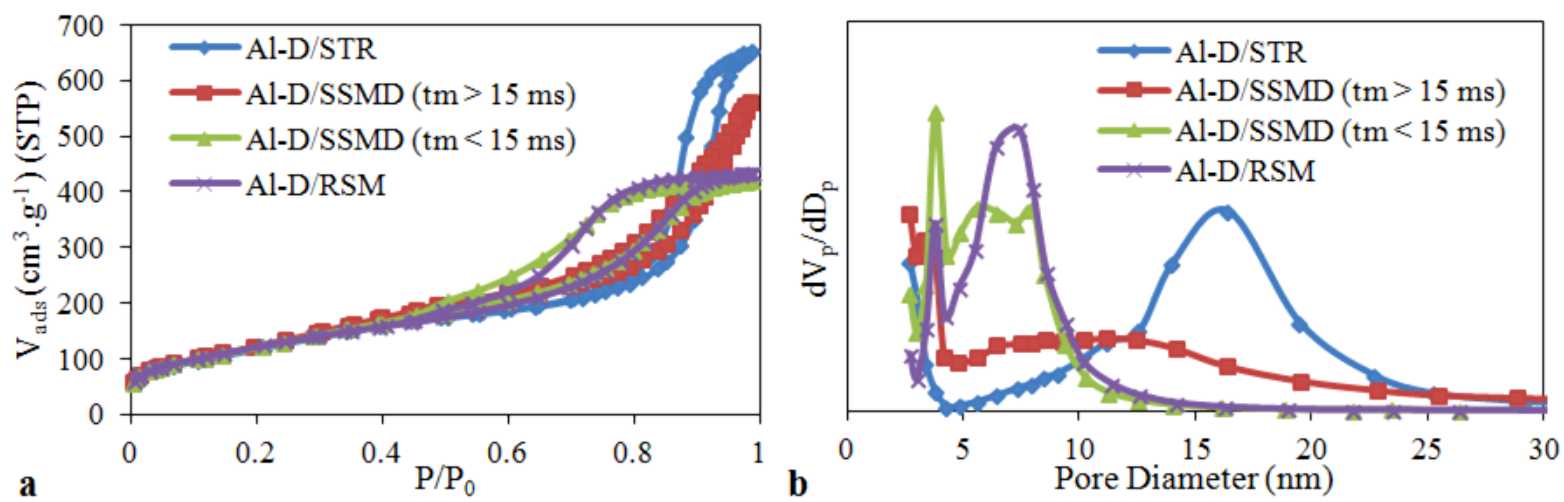

Fig. 5. (a) $\mathrm{N}_{2}$ adsorption-desorption isotherm and (b) pore size distributions of $\mathrm{NH}_{4}$-dawsonite derived alumina prepared with different mixing technologies 


\section{Conclusion}

In this study, two alumina precursors, boehmite and $\mathrm{NH}_{4}$-dawsonite, were precipitated in three different mixing technologies. The influence of micromixing time on the precursors and their respective alumina properties were evaluated.

It was observed that precipitation in a continuous fast mixer leads to a decrease of the solid porosity compared to the precipitation in a classical semi-batch STR.

However, in continuous mode, only $\mathrm{NH}_{4}$-dawsonite turns out to be sensitive to micromixing time. It is thus possible to tune the pore volume between 0.5 and $0.9 \mathrm{~cm}^{3} \cdot \mathrm{g}^{-1}$ on the derived alumina, but not the specific surface area, which always range between 400 and $450 \mathrm{~m}^{2} \cdot \mathrm{g}^{-1}$ after the calcination step.

It is also interesting to note that for given micromixing conditions, boehmite and $\mathrm{NH}_{4}$-dawsonite lead to alumina exhibiting very different textural properties. Overall, it can be observed that dawsonite derived alumina are more porous than boehmite derived alumina, with both larger mean pore diameter and larger pore size distribution. Dawsonite derived alumina also exhibit particularly high specific surface area, but part of it is due to microporosity created during the calcination step, because of their particular thermal decomposition process.

It is thus possible to get varied $\gamma$-alumina with specific porosity range using the appropriate precursor/mixing technology system (Fig. 6).

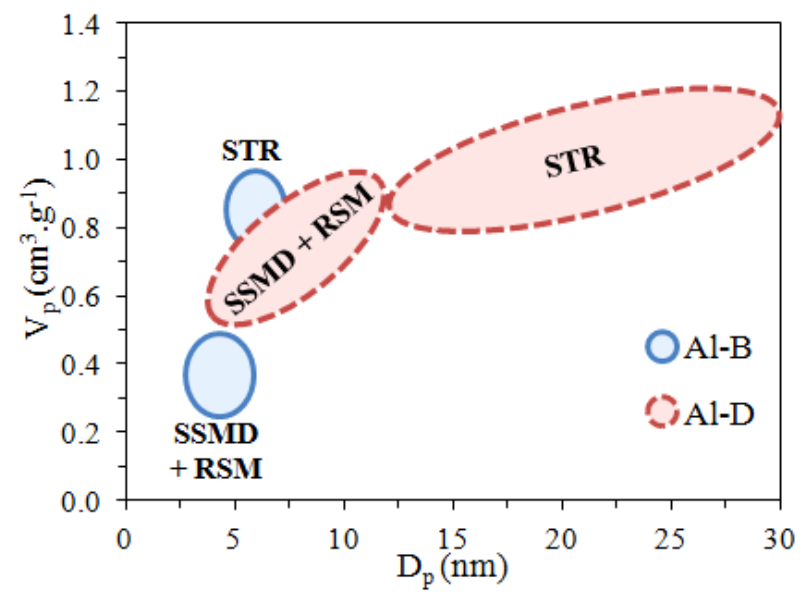

Fig. 6. $\gamma$-alumina porosity ranges covered by several precursor/mixing technology systems (STR: stirred tank reactor ; RSM: rotor-stator mixer ; SSMD: sliding surface mixing device)

\section{Acknowledgements}

The authors would like to thank the Physics and Analysis Division and the Process Experimentation Division (IFPEN) for technical assistance.

This research did not receive any specific grant from funding agencies in the public, commercial, or notfor-profit sectors.

\section{References}

[1] P. Euzen, P. Raybaud, X. Krokidis, H. Toulhoat, J.-L. Le Loarer, J.-P. Jolivet, et al., Alumina, in: F. Schüth, K.S.W. Sing, J. Weitkamp (Eds.), Handb. Porous Solids, Wiley-VCH, Weinheim, 2002.

[2] D. Papée, R. Tertian, R. Biais, Recherches sur la constitution des gels et des hydrates cristallisés 
d'alumine, Bull. Soc. Chim. Fr. 5 (1958) 1301-1310.

[3] P. Alphonse, M. Courty, Structure and thermal behavior of nanocrystalline boehmite, Thermochim. Acta. 425 (2005) 75-89. doi:10.1016/j.tca.2004.06.009.

[4] X. Jiang, N. Suzuki, B.P. Bastakoti, K.C.W. Wu, Y. Yamauchi, Synthesis of continuous mesoporous alumina films with large-sized cage-type mesopores by using diblock copolymers, Chem. - An Asian J. 7 (2012) 1713-1718. doi:10.1002/asia.201200256.

[5] B.P. Bastakoti, S. Ishihara, S.Y. Leo, K. Ariga, K.C.W. Wu, Y. Yamauchi, Polymeric micelle assembly for preparation of large-sized mesoporous metal oxides with various compositions, Langmuir. 30 (2014) 651-659. doi:10.1021/la403901x.

[6] J. Čejka, Organized mesoporous alumina: synthesis, structure and potential in catalysis, Appl. Catal. A Gen. 254 (2003) 327-338. doi:10.1016/S0926-860X(03)00478-2.

[7] M. Trueba, S.P. Trasatti, $\gamma$-Alumina as a Support for Catalysts: A Review of Fundamental Aspects, Eur. J. Inorg. Chem. 2005 (2005) 3393-3403. doi:10.1002/ejic.200500348.

[8] G. Busca, Structural, Surface, and Catalytic Properties of Aluminas, in: Adv. Catal. Vol. 57, Elsevier B.V., 2014: pp. 319-404. doi:10.1016/B978-0-12-800127-1.00003-5.

[9] M. Santiago, M.S. Yalfani, J. Pérez-Ramírez, In-line dispersion-precipitation method for the synthesis of metal-substituted dawsonites. Genesis of oxide materials with superior properties, J. Mater. Chem. 16 (2006) 2886. doi:10.1039/b607031k.

[10] A.A. Ali, M.A. Hasan, M.I. Zaki, Dawsonite-Type Precursors for Catalytic Al, Cr, and Fe Oxides: Synthesis and Characterization, Chem. Mater. 17 (2005) 6797-6804. doi:10.1021/cm0519131.

[11] J. Bałdyga, Ł. Makowski, W. Orciuch, Interaction between Mixing, Chemical Reactions, and Precipitation, Ind. Eng. Chem. Res. 44 (2005) 5342-5352. doi:10.1021/ie049165x.

[12] J. Franke, A. Mersmann, The influence of the operational conditions on the precipitation process, Chem. Eng. Sci. 50 (1995) 1737-1753. doi:10.1016/0009-2509(95)00028-4.

[13] J.-M. Rousseaux, H. Muhr, E. Plasari, Chemical reactors of special geometry for the precipitation of mineral particles, Can. J. Chem. Eng. 78 (2000) 650-662. doi:10.1002/cjce.5450780407.

[14] J.-M. Rousseaux, L. Falk, H. Muhr, E. Plasari, Micromixing efficiency of a novel sliding-surface mixing device, AIChE J. 45 (1999) 2203-2213. doi:10.1002/aic.690451018.

[15] X. Hu, Y. Liu, Z. Tang, G. Li, R. Zhao, C. Liu, Fabrication of high-surface-area $\gamma$-alumina by thermal decomposition of AACH precursor using low-temperature solid-state reaction, Mater. Res. Bull. 47 (2012) 4271-4277. doi:10.1016/j.materresbull.2012.09.019.

[16] J. Baldyga, J.R. Bourne, Comparison of the Engulfment and the Interaction-by-Exchange-withthe-Mean Micromixing Models, Chem. Eng. J. 45 (1990) 25-31.

[17] S. Renouf, Etude d'un procédé d'émulsification : suivi rhéologique in situ dans un rhéo-émulseur et formation de gouttes primaires dans un champ d'écoulement, INPL, 2000.

[18] A.J. Kowalski, An expression for the power consumption of in-line rotor-stator devices, Chem. Eng. Process. 48 (2009) 581-585. 